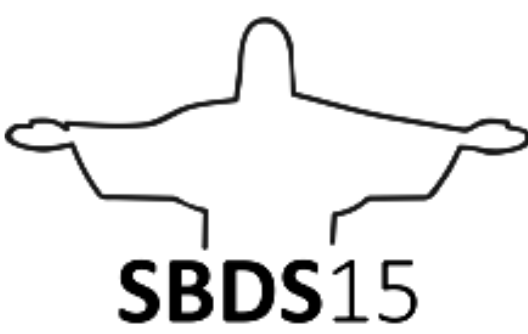

5 SIMPÓSIO DE DESIGN SUSTENTAVELL
Rio de Janeiro - RJ

11 de novembro a 13 de novembro de 2015

\title{
INTERVENÇÕES DO DESIGN PARA AUMENTAR A VIDA ÚTIL DOS PRODUTOS DE MODA NA FASE DE USO
}

\author{
Nayara Chaves Ferreira Perpétuo \\ Universidade Federal do Maranhão \\ nayara_chaves@hotmail.com \\ Raquel Gomes Noronha \\ Universidade Federal do Maranhão \\ raquelnoronha79@gmail.com
}

\begin{abstract}
Resumo: Os produtos de moda, como todos os outros, geram impacto desde sua concepção até o seu descarte - seja em função de sua matéria-prima, de seu processo produtivo, de sua manutenção. Contudo, é importante reconhecer que o seu descarte excessivamente precoce precisa ser revisto. Entende-se que o caminho possível não é abolir o sistema de moda, mas sim discutir a alteração da dinâmica dos seus produtos. Considera-se aqui o papel estratégico do design em oferecer possibilidades que podem ser reconhecidas pelo consumidor como melhores que as ofertadas anteriormente, capazes de permitir a mudança de comportamento, tão urgente no contexto atual. Para tanto é necessário perceber a relação simbiótica entre designer, produto e consumidor.
\end{abstract}

Palavras-chave: Design, Consumo, Produtos de Moda.

Abstract: The fashion products, like everyone else, generate impact from conception to disposal - is due to its raw material in the production process of its maintenance. However, it is important to recognize that its too early disposal needs to be reviewed. It is understood that the possible path is not to abolish the fashion system, but rather discuss changing the dynamics of their products. It is considered here the strategic role of design in offering possibilities that can be recognized by consumers as better than those offered earlier, capable of enabling behavior change, so urgent in the current context. Therefore, it is necessary to understand the symbiotic relationship between designer, product and consumer.

keywords: Design, Consumer, Fashion Products. 


\section{INTRODUÇÃO}

Certamente a questão da sustentabilidade é a maior crítica já enfrentada pela moda, porque a desafia como um todo, desde o uso de materiais e processamentos até os modelos econômicos, sistemas de crenças e valores. Percebe-se através deste enfrentamento, uma oportunidade de transformação significativa cuja figura estratégica é o design.

O papel do design no processo de transição em direção à sustentabilidade não consiste em projetar estilos de vida sustentáveis, mas sim em propor oportunidades que tornem praticáveis tais estilos (MANZINI, VEZZOLI, 2008).

Os produtos de moda geram impactos ao longo de todo o seu ciclo de vida. Contudo, o consumo excessivo e seu descarte em curtíssimo espaço de tempo são agravantes a mais que precisam ser revistos.

Figura como tema deste artigo a prática do design propondo estratégias para otimizar o uso de produtos de moda, pois ao buscar conhecer e potencializar o aumento da vida útil desses produtos, contribui-se para a diminuição do descarte, do consumo às cegas e da produção sem critérios.

Logo, não se faz uma abordagem voltada para a sustentabilidade como um fim, porque esse é um contexto muito maior do que o aqui pretendido. Objetiva-se identificar quais as estratégias de design podem ser melhor aplicadas para a otimização do uso em produtos de moda.

Volta-se o olhar para a fase de uso, pois é neste momento no qual mais intensamente observa-se a relação estabelecida entre produção e consumo, tendo em vista a participação expressiva do usuário no processo.

Para tanto faz-se, inicialmente, uma explanação do sistema de moda, tomando como suporte material principalmente o vestuário, o design e a relação estabelecida entre ambos. Uma vez que os indivíduos devem ser igualmente considerados como integrantes deste sistema, também volta-se o olhar a eles e seu comportamento de consumo. Na sequência aponta-se o desafio para o designer no desenvolvimento de produtos com foco na otimização da vida útil dos produtos. Por fim, conclui-se fazendo uma breve discussão apontando as possibilidades de intervenções do design em produtos de moda pautando-se, pela nossa abordagem, no usuário uma vez que é ele quem estabelece a relação entre moda e design.

\section{MODA, DESIGN E DESIGN DE MODA}

A influência da moda é perceptível devido ao fato dela ser um dispositivo sociocultural, percebido e mostrado como expressão do desejo do novo e a expressão da individualidade humana, além de alimentar o consumo. Ela é propagada pelas mudanças e transformações que destroem os velhos hábitos, buscando formas estéticas originais, experimentais e inovadoras para o estabelecimento de outras possibilidades de identificação.

Godart (2010) concebe a moda como um fato social total que navega entre imitação e diferenciação, entre indivíduos e sociedade. Formada por um conjunto de instituições que produzem vestuários portadores de significado que os indivíduos utilizam para suas 'representações' identitárias.

Concebida no ocidente moderno, enquanto estética industrial, a moda influencia e é percebida na indústria dos automóveis, embalagens, objetos de uso diário, podendo ser encontrada também no mobiliário das nossas casas, arquitetura, 
na gastronomia, na linguagem e nas maneiras, nos gostos e nas ideias etc. Logo, não está ligada a um objeto específico e é um equívoco tentar defini-la sem que sejam considerados seus aspectos simbólicos. Contudo, é o vestuário, com toda sua heterogeneidade, que mais encarnou significativamente o processo de moda, visto que é a luz das mudanças nos estilos ${ }^{1}$ de vestir, que se encontra representada com clareza a manifestação da efemeridade.

A moda, portanto, conforme aponta Godart (2010) pode ser entendida sob duas concepções distintas. A primeira é a da indústria do vestuário, na qual observa-se a atuação de profissionais e empresas que não produzem apenas o produto de moda, mas difundem a ideia e a cultura de moda. Por meio dessa indústria encontra-se o consumo de produtos pelos indivíduos, grupos ou classes sociais como forma de definirem sua identidade. Esta por sua vez, não consiste em uma representação individual, mas sim coletiva, já que se vale das convenções culturais às quais estamos imersos e que nos moldam. Já a segunda, é a concepção de uma mudança social específica, sendo esta regular (entre períodos de tempo intervalados, constantes e curtos) e não cumulativa (substituição) manifestada em múltiplas esferas da vida social. Tomando o vestuário como exemplo, observa-se a regularidade das mudanças propostas nos lançamentos das coleções, normalmente de forma sazonal (primavera/verão e outono/inverno). Elas também não são cumulativas, uma vez que não somente acrescentam mudanças, mas substituem as passadas. Agora, distanciando-se do vestuário, percebe-se a presença da moda como mudança na pilosidade facial masculina, no uso de novas ideias de gestão e nos nomes dados pelos pais aos recém-nascidos. Logo, ela "é um modo ou costume que prevalece em uma determinada época, reflete os valores e os costumes de uma sociedade em um período do tempo" (KELLER, 2007, p. 10).

A moda como indústria produz estilos caracterizados por mudanças regulares e não cumulativas, logo percebe-se a ligação existente entre as duas concepções. Entretanto, tal ligação não é indissociável, pois a partir dos exemplos observa-se que algumas questões da moda ultrapassam os aspectos da indústria, assim como aspectos da indústria não estão associados às mudanças regulares e não cumulativas, tais como os processamentos têxteis.

Diante dessas duas possibilidades de compreensão da moda, nesse trabalho opta-se por trabalhar prioritariamente a concepção de moda na qualidade de indústria, no entanto, a moda como mudança regular e não cumulativa não será ignorada, sobretudo quando estiver ligada à primeira concepção.

O produto de vestuário ganha valor de moda ainda durante seu processo de produção e para isso conta com a participação de um agente fundamental nesse processo: o design.

Normalmente as definições de design estão associadas a etimologia da palavra. Tais definições quando importadas para o Brasil ocasionaram e ocasionam uma série de confusões e esvaziamento de seu sentido. Na opinião pública design é comumente associado à estética, distanciando-se gradativamente da ideia de solução inteligente de problemas. Tal distanciamento aproximou o design do efêmero, do obsoletismo rápido, da glamourização dos objetos (BONSIEPE, 2011).

\footnotetext{
${ }^{1}$ Estilo é um modo distinto ou elegante de ser, agir ou viver, que vai além do vestir (KELLER, 2007, p. 10).
} 
Contudo, neste trabalho entende-se design a partir de uma definição institucionalizada dada pelo International Council of Societies of Industrial Design (ICSID) como uma atividade cujo objetivo é estabelecer as qualidades multifacetadas de objetos, processos, serviços e seus sistemas em ciclos de vida completos, melhorando ainda mais - em consonância com outras profissões relacionadas - o valor da vida.

Quando focado no desenvolvimento de projetos para a produção de artefatos de consumo, especificamente os de vestuário, o design passa a ser entendido como design de moda. Permeia todo o processo e sua característica projetiva é mais claramente observada no momento da concepção de uma coleção (conjunto articulado de peças de vestuário) com: a definição dos artefatos a serem desenvolvidos, necessitando planejamento, pesquisa em diversos âmbitos tais como a histórica, a cultural e a mercadológica e definição de tendências. Para então continuar o processo são selecionadas a modelagem, os tecidos, cartela de cores, detalhes de aviamentos fazendo essencial a ergonomia. Posteriormente, confecciona-se a peça piloto ou protótipo, podendo este ainda sofrer alterações até que possa ser testado em modelo compatível ao tamanho escolhido. Somente após essas etapas é dada a consolidação do produto para confecção em larga escala. Assim, demonstra-se todo o raciocínio projetual para configurar um produto de vestuário que, concebido considerando tendências ${ }^{2}$, pode inserir-se no mercado e ser legitimado, através do uso, também como um produto de moda.

Em Bourdieu (2004) encontramos transformação de objetos inertes, as matérias-primas, em objetos "mágicos" portadores de status e diferenciação social, de um significado expresso quer seja por uma cor, forma ou marca. No processo de concepção, os produtos de moda adquirem vida própria em um jogo de sedução para possuir e ser possuído. Esse jogo de interesses mútuos se vale dos recursos usados pela comunicação mercadológica, que atuam sob a lógica dos sonhos de consumo.

A partir dos conceitos estabelecidas até então, delimita-se mais um dos objetos desta pesquisa: o produto de moda. Neste trabalho são considerados apenas os itens do vestuário de características têxteis que compreendem as delimitações de roupas e que também possuem o valor de moda, ou seja, são aceitos e consumidos em massa em curto período de tempo.

\subsection{Comportamento de Consumo de produtos de moda}

Canclini (2010) a partir de um apanhado multidisciplinar propõe uma definição: "o consumo é um conjunto de processos socioculturais em que se realizam a apropriação e os usos dos produtos" (CANCLINI, 2010, p. 60).

A sociedade é induzida ao consumo, através das empresas munidas de seus apelos de marketing, criando carências e desejos (materiais e simbólicos) constantes. Nesse contexto, muitas vezes os indivíduos passam a ser reconhecidos, avaliados e julgados por aquilo que consomem. Tal comportamento não é apenas externo ao indivíduo e ele mesmo passa a se auto avaliar pelo que consome, externando sua perspectiva de mundo e as conexões estabelecidas entre os valores éticos, escolhas políticas, relação com o meio-ambiente e outros.

\footnotetext{
${ }^{2}$ segue-se o pensamento de Dario Caldas (2004) que conceitua tendência como o "espírito do tempo" ou zeitgeist fazendo referência ao clima intelectual e cultural de uma época, ao espírito e aparência de uma geração.
} 
Haja vista que ninguém faz moda sozinho, ela é um fenômeno sociológico. É essencial que haja consenso, indivíduos que acreditem, concordem e consumam esta ou aquela ideia tornando-a moda. Doris Treptow (2007) aponta as seguintes fases para o ciclo da moda: lançamento, consenso, consumo, massificação e desgaste.

Para a moda surgir na escala social, Jones (2005) aponta duas maneiras sendo: efeito trickle-down (gotejamento) e efeito bubble-up (ebulição). O primeiro inicia no topo da elite da moda através da exposição da mídia de onde será copiado por mercados populares e produzido em larga escala com acesso ao público em geral. O segundo faz o caminho inverso. Nasce no seio social, normalmente por meio de um grupo que desenvolve um estilo de vestir. Tal atitude desperta o mercado da moda que começa a divulgá-lo. A divulgação é fortalecida por formadores de opinião que reconhecem o estilo das ruas e adotam versões mais sofisticadas do mesmo.

No efeito trickle-down, o designer de moda concebe o produto baseado nas tendências e introduz no mercado com criatividade e inovação, a custos altos e com pouco consumo. Posteriormente, à medida os produtos alcançam popularidade, as pessoas passam a copiar por preços mais acessíveis e qualidade inferior. Independente do ponto de surgimento da moda, ou nas ruas ou nas passarelas, há o pressuposto de ser aceito e imitado. Quando ocorre o auge da cópia do produto, ou a perda da aura, segundo Walter Benjamin (2000), começa o declínio e a rejeição, abrindo espaço para o surgimento de outras novidades. Logo, a partir do momento que é amplamente difundida, ou seja, o que antes era feito originalmente por poucos, perde a autenticidade, se espalha e passa a ser praticado por todos, gradualmente uma moda morre, pois perde o status de novidade.

Regida por estações, normalmente o tempo máximo da vida de uma coleção é de três meses. Ligada a essa configuração está a mudança no comportamento do consumidor. Isso implica diretamente no processo industrial marcado por tempo restrito e intensificação do trabalho.

Pensar o consumo de moda é ir além do produto, sua produção e seu ciclo de vida. É também gerenciar a obsolescência produzida, não pelo desgaste do produto, ou perda de suas funções, mas aquela que é motivada pela aparência e pela moda, condicionando o fim da vida de alguns objetos enquanto suas funções ainda parecem válidas (KAZAZIAN, 2005).

É comum na indústria da moda haver uma minimização dos aspectos tangíveis do produto, percebidos pelos cinco sentidos humanos. Ao se considerar a roupa, a função vestimentar está diretamente ligada às necessidades corporais, seja em relação ao conforto, à higiene, à segurança, à durabilidade, etc. Assim, um produto dificilmente é consumido apenas pelo seu valor de uso, mas por diversos valores agregados a ele que o transforma em bem simbólico. Logo, a principal razão que leva à sua eliminação não é a obsolescência tecnológica, mas sim a simbólica, estética e cultural.

Dentre os motivos que condicionam o uso de produtos de moda, destacase o adorno em detrimento da proteção e do pudor. Tal motivo sobressai graças ao valor simbólico e cultural que está associado ao desejo de manifestar a identidade social, pertença em grupo étnico, posicionamento político entre outras intenções. Ele está relacionado ao "espírito do tempo" e à condição de interpretação do produto em um referencial estético (KRUCKEN, TRUSEN, 2009). 
Comumente esses valores são potencializados por mecanismos sofisticados e provocativos que direcionam à noção felicidade. As mídias, especialmente os meios de comunicação de massa são protagonistas na propagação da ilusão de que determinado produto é absolutamente necessário, desejável, imprescindível para seus possíveis consumidores.

Diversos fatores psicológicos ajudam a explicar porque os indivíduos são motivados a estar na moda, sendo eles a conformidade social, busca pela vaidade, criatividade pessoal e atração sexual. Em geral os consumidores têm necessidade de serem únicos, quase que como uma auto-afirmação, mas não tão diferentes a ponto de perderem sua identidade social.

Entre as necessidades envolvendo a moda encontra-se talvez a mais importante: o desejo, necessidade humana moldada pela cultura e pela personalidade individual. Resumidamente, o desejo aqui em questão, dos produtos de moda, adquire delimitação própria contemplando algumas dimensões sendo elas: aparecer, ser, parecer, idealizar e inovar.

A dimensão do aparecer, tem por objetivo o consumo de moda para chamar atenção, se destacar na multidão, ter mais olhares sobre si do que as outras pessoas; a dimensão do ser expressa a preocupação em atender as pressões sociais e fazer parte de grupo com o qual se identifique; a dimensão do parecer reflete a vaidade e é a força motriz para o consumo de moda; a dimensão do idealizar é voltada para o outro, para o que acredita ser a imagem ideal, a projeção; a dimensão do inovar representa o desejo de mostrar cultura, atualidade, informação, estar na moda é "estar por dentro", é ser in (MIRANDA, GARCIA, SOUZA LEÃO, 2003).

\section{NOVOS PARADIGMAS PARA PRODUTOS DE MODA: um desafio para o design}

No âmbito do projeto de produtos e não somente nele, o papel do design passa a ser ainda mais fortalecido como mediador e estratégico. $O$ design centrou-se inicialmente na adoção de medidas paliativas, tais como abordagens com foco nos resíduos provenientes dos produtos e processos industriais. Posteriormente voltou-se para a intervenção com design no decorrer do ciclo de vida dos produtos. Recentemente de forma mais abrangente e efetiva os estudos começam a trabalhar com comportamento, cultura de consumo e projeção de estilos de vida.

O papel do design no contexto da inovação sociocultural, distanciando da ideia arrogante de que ele unicamente pode mudar gostos e preferências de uma sociedade, deve ser claro e consciente. "O designer, portanto, assume o papel de facilitador, ou agente ativador, de inovações colaborativas, promovendo interações na sociedade" (KRUCKEN, 2009, p. 48).

Contudo, uma mudança de paradigmas também no campo do design só será possível com o aprofundamento de suas propostas na constante avaliação comparada das implicações ambientais, nas diferentes soluções técnica, econômica e socialmente aceitáveis e deve considerar, ainda, durante a concepção de produtos e serviços, todas as condicionantes que os determinem por todo o seu ciclo de vida dos produtos.

No conceito de ciclo de vida trabalhado por Manzini e Vezolli (2008) considera-se desde os recursos necessários para a produção dos materiais que 0 compõe o produto até o tratamento destes mesmos materiais após o descarte. Assim 
os diversos processos são agrupados em fases, sendo elas: pré-produção, produção, distribuição, uso e descarte.

Sem o aporte estratégico do design, o ciclo de vida de um produto não expande para além dos limites do redesign de produtos já concebidos; e sem a análise do ciclo de vida dos produtos, o design para a sustentabilidade se perde no vazio de fundamentação concreta (MANZINI, VEZZOLI, 2008).

"Enquanto buscamos melhorar os produtos de moda é vital refletir de maneira ampla e profunda ao tomar decisões" (FLETCHER, GROSE, 2011, p.11). A visão abrangente norteadora das práticas sustentáveis não deve ser excluída de cada fase da indústria da moda, ou seja, não é apenas o produto que deve ser projetado, mas todos os processos associados ao cumprimento dessa função.

Vezzoli (2010) aponta como requisitos necessários: minimizar o uso de recursos; selecionar recursos e processos de baixo impacto ambiental; otimizar a vida dos produtos; estender a vida dos materiais e facilitar a desmontagem. Ao direcionar tais requisitos para produtos de moda há uma adequação natural, o mesmo ocorreria com quaisquer outros produtos, uma vez que cada um possui suas peculiaridades.

Inicia-se com a escolha das fibras têxteis, fabricantes, acabamentos de tecidos que devem ser constituídos por uso mais eficiente de recursos, melhorias nos direitos dos trabalhadores, redução do uso de substâncias químicas e diminuição da poluição.

A partir dessas escolhas conscientes, o designer precisa ser ativo juntamente com o engenheiro têxtil na escolha também dos processamentos das fibras considerando seus efeitos sobre a água, a qualidade do ar, a toxicidade do solo e a saúde das pessoas e dos ecossistemas. Devem ser ponderados sequencialmente 0 desperdício mínimo no corte e na costura, uso de metais e aviamentos de baixo impacto. Tanto para ser confeccionada quanto para chegar ao consumidor ainda há uma enorme infraestrutura de recursos que circula sem critérios sustentáveis, principalmente quanto à emissão de carbono com o transporte entre longas distâncias no planeta, e que estão sob a responsabilidade de quem realiza os pedidos de compra de materiais e produtos. Ao chegar aos cuidados do consumidor, o produto já precisa ser concebido para gerar o mínimo de impacto na sua manutenção - lavar, secar e passar e, para que isso seja realmente possível, o consumidor precisa ser bem informado através de etiquetas eficazes.

Finalmente deve ser considerado o destino final das peças, considerando as estratégias para coleta de resíduos, reutilização, restauração. Em roupas, a reciclagem é uma estratégia atualmente problemática, já que a maioria das peças de vestuário são feitas de materiais mistos e construída de tal maneira que eles não são fáceis de desmontar (VEZZOLI et al, 2014).

Embora muito seja feito para inovar e melhorar as credenciais de sustentabilidade, o maior desafio consiste em equilibrar os sistemas de produção, modelos de negócios que promovem e vendem as peças e o comportamento de quem compra.

\section{INTERVENÇÕES DO DESIGN EM PRODUTOS DE MODA}

A vida útil de um produto e seus materiais, em condições normais de uso, é medida pelo tempo que este pode durar conservando as próprias capacidades e o próprio comportamento em um nível padrão aceito, ou melhor, preestabelecido. A 
análise da vida útil de um produto é variável em relação a determinadas funções, dentre elas: a previsão do tempo de vida de um produto, a quantidade de uso, o tempo de duração das operações ou a vida de prateleira (armazenagem) (MANZINI, VEZZOLI, 2008).

O prolongamento da vida útil do vestuário de moda, reflete diretamente no aumento da fase de uso de seu ciclo de vida. O uso prolongado do produto consequentemente adia o seu descarte. A desaceleração do descarte, por sua vez, desacelera também a necessidade de consumo de um novo produto, que acaba desacelerando a necessidade de produção do mesmo (LIMA, VICENTINI, 2013). Resumidamente através da desaceleração, tanto do sistema como um todo como também da dinâmica do ciclo de vida do produto, atinge-se um efeito dominó que oportuniza uma aproximação da sustentabilidade.

Vezzoli (2008) propõem indicações para intensificar o uso e ir de encontro ao modelo de descarte difundido. Deve-se orientar o projeto para produtos multifuncionais, que tenham componentes substituíveis em comum, ou ainda, para produtos de funções integradas. Para além dessas indicações, conceber produtosserviços voltados para o uso compartilhado ou voltados para o uso coletivo são as que possuem efeito mais significativo, visto que o ideal de sustentabilidade está mais próximo da atitude do que efetivamente dos processos.

São iniciativas cabíveis e já praticáveis em produtos de moda: o desenho de peças modificáveis ou personalizáveis como forma de solucionar problemas como variação de tendências de moda ou mudanças corporais, design de peças multifuncionais ou reversíveis diminuindo a necessidade de consumo e o oferecimento do aluguel de roupas, prática mais popular quando se trata de roupa de trabalho ou peças que terão uso específico em curto período de tempo (SALCEDO, 2014).

Vezolli et al (2014) justificam que no contexto do produto de moda, o elemento de intimidade, a profunda conexão com a construção de identidade, e como a roupa é avaliada em contextos sociais fazem este grupo de produtos menos adequados para, por exemplo alugar por longo prazo. Por outro lado, estas mesmas questões sobre o significado simbólico de roupas abrem oportunidades para serviços de design e personalização da peça.

Tornar visível à sociedade a história por trás dos produtos contribui significativamente na conexão com as emoções e na criação de laços entre todos os participantes da cadeia produtiva da peça. A co-criação, na qual o consumidor tem a oportunidade de tomar para si parte no processo de design atuando na concepção ou de tomada de decisões, tende a estimular um senso de responsabilidade maior no consumidor. Estas são estratégias que, através das emoções, geram mais apego ao produto e consequentemente adiam sua eliminação.

A atratividade do produto sustentável deve perpassar inclusive pela estética, indispensável no contexto da moda. Ela deve ser vista mais que como uma melhoria, indo além das cores e formas do produto, em todo o conjunto de características percebidas que, de certo modo, possam ser cativantes.

São relevantes também as iniciativas para a concepção do design de forma a retardar ou facilitar o conserto da peça. No caso das roupas, são exemplos dessas ações os botões ou outros aviamentos reservas que acompanham os produtos; etiquetas informacionais eficientes. 
Por razões ambientais seria simplesmente melhor consumir menos. No entanto, a maioria dos consumidores não estão dispostos a reduzir o consumo. Assim surgem os conceitos de slow fashion e fast fashion. O Slow fashion é projetado para apontar para mais utilização, uma vida útil mais longa de produtos através de durabilidade e alta qualidade. Já o conceito fast fashion é mais adequado para os consumidores que precisam para seguir tendências de perto e construir uma identidade pessoal com símbolos externos de moda (especialmente grupos de consumidores mais jovens); daí a vida útil do produto é curto. Logo, o impacto da manutenção tem de ser minimizado (por exemplo, não lavar ou não passar), e os materiais devem ter um baixo impacto ambiental e ser recicláveis ou biodegradáveis (VEZZOLI et al, 2014).

Fletcher e Grose (2011) propõe um futuro no qual a compra já não está no centro da experiência de moda, mas é apenas um de seus aspectos, que também incorporam a energia criativa dos indivíduos, ao considerar a durabilidade ideal de cada peça e renovar seu guarda-roupa e a si mesmo de novas maneiras.

Os objetos consumidos fazem parte de um processo informacional, transmitem mensagens e são plenos de significados. Comunicam, dentro de dada cultura, quem tem mais ou menos poder aquisitivo, é mais talentoso, mais elegante etc. Comumente tal processo remete a questões de distinção pautadas em riqueza financeira e acúmulo de bens, contudo tal distinção também pode ocorrer graças ao sacrifício de não possuir ou consumir pautando-se em critérios.

Desse modo, uma vez que o vestuário de moda é concebido a partir do desenvolvimento sustentável, o consumidor através do uso destes, poderá comunicar que é um sujeito consciente, sensível à mudança de paradigma e que se preocupa com as futuras gerações e a preservação do planeta.

Uma vez que o consumidor adquire comportamento de consumo consciente passa a desempenhar papel fundamental na valorização e preservação dessas dimensões de qualidade e torna-se um propagador de um novo discurso.

Já que as mudanças na moda dependem da cultura e dos ideais sociais que a compõem, comumente incorre-se no entendimento da incompatibilidade total da moda no contexto do desenvolvimento sustentável. Entretanto, esta também pode ser uma saída, pois sob a aparentemente tranquila superfície da cultura estão intensas correntes psicológicas, das quais a moda rapidamente capta a direção. Então, se em uma sociedade democrática, onde existem diversas iniciativas e movimentos para estabelecer o desenvolvimento sustentável, a moda rapidamente irá incorporá-lo (SCHULTE; LOPES, 2008).

Neste caso a responsabilidade pela mudança não é única. Não será somente o design propondo possibilidades para práticas sustentáveis tornarem-se moda, nem a moda destituída das materialidades desenvolvidas pelo design para a sustentabilidade.

Uma vez refletindo o anseio social por mudança no processo produtivo e consumo consciente, a moda deve ser percebida como aliada do desenvolvimento sustentável, por meio do design, e não como uma inimiga como é vista atualmente.

\section{CONCLUSÃO}

As questões que surgem a partir desse estudo podem ser resumidas na necessidade de busca por um aprofundamento das estratégias para aumento da vida 
útil de produtos do vestuário com valor de moda implementadas no mercado. Para isso o levantamento contínuo dos interesses dos consumidores destes produtos, dado à sua essência efêmera, é relevante.

É importante ter a clareza de que nem sempre a otimização da fase de uso possibilita essencialmente um ganho socioambiental, principalmente em detrimento de sua manutenção ou ainda da manutenção equivocada. Para tanto deve-se investigar não só a aceitação dos consumidores para com os trabalhos desenvolvidos pelas empresas, mas também as ações individuais e coletivas espontâneas desenvolvidas em prol do mesmo objetivo, quer seja através do compartilhamento, doação ou revenda de produtos ainda em bom estado de uso ou customização e reparo de peças.

Assim, cabe aos integrantes do campo do design reverem seu papel nesse cenário, propondo discussões e implementando pesquisas que possam vir a fundamentar sua prática não só projetual, como também estratégica. Além de refletir continuamente sobre nossos ecléticos papéis, ora designers, ora consumidores, de maneira responsável.

\section{REFERÊNCIAS}

BENJAMIN, Walter. A obra de arte na época de sua reprodutibilidade técnica. In: ADORNO et al. Teoria da Cultura de massa. Trad. de Carlos Nelson Coutinho. São Paulo: Paz e Terra, 2000. p. 221-254.

BONSIEPE, Gui. Design, cultura e sociedade. São Paulo: Blusher, 2011.

BOURDIEU, Pierre. O Costureiro e sua Grife: Contribuição para uma teoria da magia. In: A Produção da Crença: Contribuição para uma economia dos bens simbólicos. São Paulo: Zouk, 2004.

CALDAS, D. Observatório de Sinais - Teoria e Prática da Pesquisa de Tendências. Rio de Janeiro: Editora Senac RJ, 2004.

CANCLINI, N. G. Consumidores e Cidadãos. 8. Ed. Rio de Janeiro: Editora UFRJ, 2010.

FLETCHER, Kate; GROSE, Lynda. Moda e sustentabilidade: design para mudança. 1 ed. São Paulo: Editora Senac São Paulo, 2011.

GODART, Frédéric. Sociologia da moda. São Paulo: Editora Senac São Paulo, 2010.

INTERNATIONAL COUNCIL OF SOCIETIES OF INDUSTRIAL DESIGN - ICSDI. Definition of design. Disponível na internet por http em: <http://www.icsid.org/about/about/articles31.htm>. Acesso em 17 jun. 2015.

JONES, Sue Jenkyn. Fashion design: manual do estilista. São Paulo: Cosac Naify, 2005.

KAZAZIAN, Thierry. Haverá a idade das coisas leves: Design e desenvolvimento sustentável. São Paulo: Senac, 2005.

KELLER, Paulo Fernandes. O Trabalho Imaterial do Estilista. Revista Teoria \& Sociedade. UFMG. Belo Horizonte, n. 15.2, 2007.

KRUCKEN, Lia; TRUSEN, Christoph. A comunicação da sustentabilidade de produtos e serviços. In MORAES, Dijon de; KRUCKEN, L.(Org.). Cadernos de Estudos avançados em design: Sustentabilidade I. Barbacena: EdUEMG, 2009 p. 59-68. 
LIMA, Verena; VICENTINI, Cláudia. O prolongamento da vida útil do vestuário de moda como alternativa para a redução de seu impacto socioambiental. In: COLÓQUIO DE MODA, 9, 2013. Fortaleza. Anais... Ceará: 2012.

MANZINI, Ezio; VEZZOLI, Carlo. O desenvolvimento de produtos sustentáveis. Os requisitos ambientais dos produtos industriais. São Paulo: Editora da Universidade de São Paulo, 2008.

MIRANDA, Ana Paula de; GARCIA, Carol; SOUZA LEÃO, André Luiz Maranhão de. Moda e envolvimento: cada cabide, uma sentença. Revista Interdisciplinar de Marketing, v. 2, n. 2, p. 38-49, 2003.

SCHULTE, Neide Köhler; LOPES, Luciana. Sustentabilidade Ambiental: Um Desafio Para a Moda. Modapalavra e-periódico Ano 1, n.2, ago-dez 2008, pp. 30 - 42.

SALCEDO, Elena. Moda ética para um futuro sustentável. São Paulo: GGmoda, 2024.

TREPTOW, Doris. Inventando moda: Planejamento de coleção. 4 ed. Brusque: D. Treptow, 2007.

VEZZOLI, Carlo et al. Product-Service System Design for Sustainability. Sheffield, UK: Greenleaf Publishing, 2014.

VEZZOLI, Carlo. Design de sistemas para a sustentabilidade: teoria, métodos e ferramentas para o design sustentável de "sistemas de satisfação". Salvador: EDUFBA, 2010. 